REVISTA DE DERECHO UNED, núm. 6, 2010

\title{
EL PLAZO PARA EJERCITAR EL DERECHO DE RETRACTO ARRENDATICIO RÚSTICO
}

\author{
Begoña Flores GonZÁlez \\ Profesora colaboradora de Derecho Civil de la UNED. \\ Doctora en Derecho
}

Resumen: Este trabajo versa sobre el plazo para ejercitar el retracto arrendaticio regulado en la Ley de Arrendamientos rústicos de 2003, acompañado de un estudio específico de la jurisprudencia del Tribunal Supremo.

Palabras clave: Retracto. Plazo de ejercicio. Jurisprudencia del Tribunal Supremo.

Abstract: The present paper deals with the term to exercise the right to repurchase set at the Rustic Leases Act 2003, with specific investigation of the jurisprudence of the Supreme Court.

Sumario: 1. Introducción.-2. La notificación de la escritura pública de transmisión.-3. El conocimiento de la transmisión.-4. Conclusiones.

\section{INTRODUCCIÓN}

El artículo 22 de la Ley de Arrendamientos Rústicos de 2003 (en adelante LAR) concede al arrendatario un plazo de sesenta días hábiles para ejercitar el derecho de retracto arrendaticio rústico. En el citado precepto se establecen dos momentos de arranque para computar el referido plazo:

$1^{\circ}$. El apartado 3 del artículo 22 LAR de 2003, último inciso, establece como dies a quo del plazo aquél en que el arrendatario hubiere recibido la notificación fehaciente de la escritura de enajenación. 
$2^{\circ}$. En cualquier otro caso, el plazo se computará a partir de la fecha en que por cualquier medio el arrendatario haya tenido conocimiento de la transmisión de conformidad con el artículo 22.3, segundo inciso del párrafo segundo LAR de 2003. Esto es, cuando el propietario y el comprador llevan a cabo la transmisión de la finca ignorando el derecho de adquisición que corresponde al arrendatario. En este caso si el arrendatario toma conocimiento de la transmisión efectuada por cualquier otra vía comenzará a correr el plazo de ejercicio del retracto.

Esto es, el criterio de la LAR de 2003 es que el plazo se cuenta desde que reciba la notificación de la escritura pública y, a falta de notificación, desde que conozca, por cualquier otro medio, la transmisión. De hecho la STS de 28 de febrero de 1996 (RJA 2232) mantiene la relación de igualdad entre notificación y conocimiento exógeno de la transmisión para iniciar el cómputo del plazo para ejercitar el retracto cuando dice que «en defecto de notificación, el plazo para el ejercicio del retracto es de sesenta días hábiles a partir de la fecha en que por cualquier medio el arrendatario haya tenido conocimiento de la transmisión», y aclara que "el conocimiento exacto y completo de la transmisión por el arrendatario excluye la necesidad de una notificación posterior». Quiere decir que si el arrendatario conoce la transmisión antes de que el adquirente proceda a comunicar el contenido de la escritura de enajenación, dicho conocimiento será el que determine el arranque del plazo previsto para el retracto. No es necesario que se trate de un supuesto de omisión absoluta de la notificación. La solución será idéntica en aquellos supuestos en la notificación se realiza con posterioridad al momento en que el arrendatario llegue a conocer la transmisión por otros medios. En definitiva el conocimiento anticipado de la transmisión hace inaplicable el artículo 22.3 LAR de 2003, procediendo lo previsto en el artículo 22.2 párrafo segundo.

El plazo de sesenta días que concede la legislación de arrendamientos rústicos para el ejercicio del retracto es de caducidad como consideran de manera unánime en la actualidad doctrina y jurisprudencia $^{1}$. De hecho se dan todos los rasgos distintivos del plazo de caducidad. Se trata de un plazo breve, el cómputo del plazo se inicia cuando el arrendatario conoce la transmisión de la finca arrendada,

1 SSTS de 25 de septiembre de 1950 (RJA 1281), 26 de enero de 1954 (RJA 68), 28 de enero 1969 (RJA 133), 30 de octubre 1972 (RJA 4672), 15 de junio de 1972 (RJA 3546), 6 de febrero de 1979 (RJA 437), 18 de octubre de 1980 (RJA 3269), 17 de junio de 1981 (RJA 2572), 16 de febrero 1982 (RJA 741), 30 de junio 1983 (RJA 3695), 21 de 
finalizando inexorablemente una vez transcurridos sesenta días hábiles desde la fecha en que el arrendatario obtuvo dicho conocimiento. Si dentro de ese lapso de tiempo no se ejercita el retracto, el derecho se extingue definitivamente; es decir, el retracto se concede al arrendatario únicamente para que sea ejercitado dentro del plazo prefijado. Puig Brutau puntualiza que lo que caracteriza al plazo de caducidad es que "conocido su momento inicial se sabe con certeza cual va a ser su momento final $»^{2}$. Y lo que es más importante, se dan los motivos de fondo que aconsejan someter un derecho a un plazo de esta índole. Explica Puig Brutau que el establecimiento de un plazo de caducidad está íntimamente ligado a la naturaleza del derecho que se sujeta a este tipo de plazo. A juicio de este autor: "[l] os derechos sometidos a caducidad son casi siempre derechos potestativos, en el sentido de que atribuyen a una persona la potestad de producir, mediante su declaración de voluntad, la creación, modificación o extinción de una relación jurídica, con eficacia respecto a otros sujetos de derecho. Éstos no están propiamente en la situación de obligados, como es el caso de los derechos que pueden perder su eficacia a consecuencia de la prescripción extintiva, sino que están sometidos a tener que admitir los efectos que resulten del ejercicio derecho potestativo, que por ello mismo ha de tener efecto en un tiempo preciso". Además este autor, tras estas líneas, incluye expresamente a los derechos de tanteo y retracto en esta categoría ${ }^{3}$. Años antes se había expresado en términos muy parecidos la STS de 11 de mayo de 1966 (RJA 2419) cuando dice que la caducidad o decadencia de un derecho surge cuando la Ley o la voluntad de los particulares señalan un término fijo para la duración de un derecho, de tal modo que transcurrido ese término no puede ya ser ejercitado, refiriéndose a los llamados derechos potestativos, y más que a ellos probablemente

octubre de 1985 (RJA 4957), 30 de abril de 1990 (RJA 2812), 12 de febrero de 1991 (RJA 1198), 14 de noviembre de 1991 (RJA 8114), STS de 6 de febrero de 1996 (RJA 834), 21 de marzo de 1996 (RJA 2232), 3 de abril de 2001 (RJA 3992), 14 de junio de 2004 (RJA 5055), 23 de noviembre de 2006 (RJA 9025), 17 de enero de 2007 (RJA 670), 19 de enero de 2007 (RJA 1266), 9 de octubre de 2007 (RJA 6810), 13 de octubre de 2008 (RJA 5689). Todas las sentencias citadas han sido dictadas en supuestos de ejercicio del retracto arrendaticio rústico. Aunque existen infinidad de sentencias que declaran de caducidad el plazo de ejercicio del retracto de comuneros, colindantes o urbano. De hecho el artículo 25.3 LAU de 1994 manifiesta expresamente que el plazo de ejercicio de los derechos de tanteo y retracto es de caducidad. Esta es una cuestión que hoy día no suscita ningún tipo de duda.

2 PUIG BRUTAU, José, Caducidad y prescripción extintiva, Bosch, Barcelona, 1986, p. 7.

${ }^{3}$ PUIG BRUTAU, José, Caducidad y prescripción extintiva, Bosch, Barcelona, 1986, p. 13. 
hablando, a las facultades o poderes jurídicos cuyo fin es promover un cambio de situación jurídica. Esto quiere decir que la caducidad se funda en la necesidad de dar seguridad al tráfico jurídico que se ve amenazada por el poder de modificación jurídica que ostenta el titular del derecho sometido a tal plazo: en el caso del tanteo y retracto arrendaticios rústico la pretensión es evitar la incertidumbre en las transacciones jurídico- inmobiliarias ${ }^{4}$. Como afirma Puig Brutau se trata de que los derechos de modificación jurídica tengan unos límites precisos para no invadir más de lo necesario los justos intereses de los demás ${ }^{5}$.

No obstante, la intensa protección del tanteo y retracto arrendaticio rústico se manifiesta en el sistema adoptado para el cómputo del plazo. La LAR de 2003, de acuerdo con la terminología empleada en la STS de 30 de noviembre de 1967 (RJA 4915), opta por un sistema «subjetivo» de determinación del dies a quo conforme al cual sólo el conocimiento de la transmisión por el arrendatario tiene virtualidad de dar comienzo al plazo para retraer. En esta sentencia, dictada en un supuesto de ejercicio del retracto de comuneros, ex artículo 1.524 del Código civil, se clasifican los distintos sistemas de fijación de la inicial del plazo para retraer en materia de retractos legales, según estos tres criterios: «a) el "objetivo" que lo hace empezar al día siguiente del otorgamiento de la escritura de venta, prescindiendo de que el retrayente tenga o no conocimiento de la misma; b) el "subjetivo" que estima esencial aquel conocimiento para que el plazo principie a contarse y por ello impone la necesidad de que la venta se notifique al eventual retrayente (art. 48 LAU de 1964); y c) el "mixto" que distingue para el cómputo el caso de que haya habido inscripción de la transferencia en el Registro de la Propiedad o que no medie esta y, en esta última hipótesis el plazo no podrá contarse sino desde que el retrayente hubiese tenido conocimiento de la venta, tal y como dispone el párrafo primero del artículo 1.524 del Código Civil, derogatorio del artículo 1.618 de la ley Procesal».

La adopción de un sistema subjetivo para el cómputo del plazo revela el seguimiento de la regla general del artículo 1.969 del Código civil conforme al cual el plazo para el ejercicio del los derechos se computará desde el día en que efectivamente pudieron ejercitar-

4 BELLÓN GÓMEZ, Ildefonso, Arrendamientos Rústicos (su actual regulación, comentarios y jurisprudencia), Editorial Nacional, Madrid, 1942, p. 181 y PUIG BRUTAU, José, Caducidad y prescripción extintiva, Bosch, Barcelona, 1986, p. 13.

5 PUIG BRUTAU, Caducidad y prescripción extintiva, Bosch, Barcelona, 1986, p. 13 , ibidem. 
$\mathrm{se}^{6}$. Justamente si tenemos en cuenta que el arrendatario tiene la condición de tercero respecto al contrato que origina su derecho, es obvio que momento en que está en condiciones de ejercitar su derecho es aquel en que tiene conocimiento de que ha tenido lugar la venta.

Al ser un plazo de caducidad, como tiene declarado la jurisprudencia, opera de forma automática, es irrenunciable y en consecuencia puede ser apreciado de oficio por los Tribunales sin necesidad de que sea alegado a instancia de parte y no es susceptible de interrupción ${ }^{7}$. Hasta la reforma que en 1984 sufrió la LEC de 1881, hoy derogada, la jurisprudencia admitía que el plazo de caducidad del retracto fuera interrumpido por el acto de conciliación ${ }^{8}$. La razón de que así fuera descansaba en el carácter obligatorio que entonces tenía el acto de conciliación. Cuando la Ley 34/1984 suprime el carácter obligatorio del acto de conciliación con carácter previo a la presentación de la demanda, pierde sentido tal posibilidad y así lo declaran las SSTS de 21 de marzo de 1990 (RJA 1716), 7 de julio de 1990 (RJA 5781) y 14 de junio de 2004 (RJA 5055).

Por último, debe tenerse en cuenta que se trata de un plazo sustantivo y no procesal, pues se trata del ejercicio de un derecho, quedando, por ello, sometido en su cómputo a las reglas del artículo 5 del Código civil ${ }^{9}$. En consecuencia, el plazo de sesenta días hábiles para ejercitar el retracto arrendaticio debe computarse el día siguiente a aquél en que el arrendatario reciba la notificación o conozca por cualquier otro medio la transmisión.

\footnotetext{
${ }^{6}$ Véase PUIG BRUTAU, José, Caducidad y prescripción extintiva, Bosch, Barcelona, 1986, pp. 93 y 94, donde sintetiza la jurisprudencia del TS relativa al significado que debe atribuirse a la expresión "posibilidad de ejercicio», de acuerdo con la cual para que un derecho prescriba no basta con que haya nacido, lo que teóricamente lo hace ejercitable, sino que, además es necesario que pueda ser efectivamente ejercitado, siendo necesaria habitualmente la concurrencia de circunstancias adicionales.

7 SSTS de 30 de abril de 1940 (RJA 304), 25 de septiembre de 1950 (RJA 1406) y 28 de enero de 1969 (RJA133).

${ }^{8}$ Cabe citar las SSTS de 10 de marzo de 1945 (RJA 683), 25 de septiembre de 1950 (RJA 1406), 25 de noviembre de 1955 (RJA 3118), de 15 de junio de 1972 (RJA 3546), 16 de febrero de 1982 (RJA 741), 21 de octubre de 1985 (RJA 4957).

9 STS de 13 de diciembre de 1954 (RJA 2852) y STS de 15 junio de 1972 (RJA 3546).
} 


\section{LA NOTIFICACIÓN DE LA ESCRITURA PÚBLICA DE TRANSMISIÓN}

El artículo 22.3 LAR de 2003 con una dicción claramente imperativa, dispone que la escritura de enajenación se notificará de forma fehaciente al arrendatario para que pueda hacer uso del retracto en el supuesto de que se hubiesen alterado en perjuicio del arrendatario el precio y/o las restantes condiciones que se hubiesen consignado en la notificación para el tanteo, es decir, cuando se hubiere vendido en condiciones menos onerosas que las notificadas al arrendatario; si se hubiera enajenado la finca a persona distinta de la que figuraba en aquella; o cuando de la comparación entre ambas notificaciones el contenido de la primera notificación resultase ser incompleto. Estas circunstancias ponen de manifiesto que la posibilidad de ejercicio del tanteo estuvo viciada, razón por la cual se concede de nuevo al arrendatario la oportunidad de hacer efectiva la preferencia una vez producida la enajenación.

En definitiva, la notificación debe ser efectuada para que el arrendatario pueda hacer uso del retracto. Sólo si conoce la transmisión y sus condiciones podrá saber si tiene o no derecho a retraer. Por ello la Ley exige que se notifique al arrendatario la escritura de transmisión.

Aunque en el artículo 22.3 LAR 2003 no se dice sobre quién recae la carga de notificar (tampoco lo hacía su antecesor el artículo 91.2 LAR de 1980), es evidente que corresponde al adquirente que es quien sufre la sanción por su omisión: si no justifica la práctica de la notificación fehaciente de la escritura no podrá inscribir su adquisición en el Registro de la Propiedad ni, por tanto, disfrutar del régimen de seguridad que éste le ofrece. Esta es la opción más lógica si tenemos en cuenta que sólo frente a él, como nuevo propietario de la finca arrendada, se ha de ejercitar el retracto y como tal ha de transmitir al arrendatario ${ }^{10}$. La antigua LAR de 1935 en su artículo 16 imponía directamente este deber al nuevo propietario, de hecho en actualidad así lo dispone el artículo 25.3 inciso segundo LAU de 1994. Si bien, hay quien opina que hubiera sido preferible que el de-

10 GIL ROBLES Y GIL-DELGADO, Comentarios prácticos a la Ley de Arrenda-

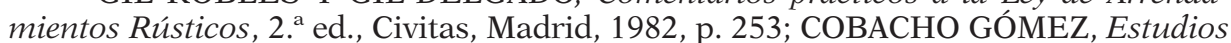
sobre la Ley de Arrendamientos Rústicos, Universidad de Murcia, Murcia, 1986, p. 179 y también ESTRUCH ESTRUCH, Jesús, Los derechos de adquisición preferente regulados en la Ley de Arrendamientos Rústicos y en la Ley de Arrendamientos Rústicos Históricos, Editorial Práctica de Derecho, Valencia, 1996, p. 99. 
ber de notificar recayese sobre el propio Notario autorizante de la escritura de transmisión al efecto de asegurar su conocimiento por el arrendatario $^{11}$.

Respecto al contenido de la notificación dispone el artículo 22.3 LAR de 2003 que se ha de notificar la propia escritura de transmisión: sólo así podrá el arrendatario saber con exactitud si la realidad coincide con la información que le fue facilitada por el propietario sobre el proyecto de enajenación. Esta notificación, como la del tanteo, ha de ser fehaciente, lo que exige que se haga notarialmente o por conciliación judicial ${ }^{12}$; y dado que lo que se debe notificar es la escritura de enajenación deberá por dichas vías procederse a entrega de copia de dicho documento.

Una vez practicada de forma fehaciente la notificación de la escritura de transmisión, el dies a quo del plazo de sesenta días hábiles para retraer comenzará al día siguiente de aquél en que el arrendatario la reciba (art. $5 \mathrm{CC}$ ). Si el arrendatario deja transcurrir dicho plazo sin ejercitar el retracto éste se extingue.

En todo caso, la jurisprudencia tiene declarado que equivale a la notificación fehaciente aquella notificación que, no obstante no adopte esta forma, produzca idéntico resultado práctico que el que se persigue con la exigencia de este requisito. Este es el caso de la STS de 7 de abril de 1986 (RJA 1842) donde anteriormente al otorgamiento de escritura pública la venta había sido realizada en documento privado con la intervención del arrendatario que manifestó en el citado documento su renuncia al retracto a cambio de una indemnización de un millón de las antiguas pesetas. El arrendatario pretende enervar la validez de la renuncia realizada alegando que no le fue notificada fehacientemente la transmisión. El Tribunal Supremo responde que la referida notificación ha sido cumplida pues no hay notificación más fehaciente que la personal intervención en el acto de enajenación de quien debía ser notificado. De forma parecida la STS de 17 de marzo de 1989 (RJA 2158) declara admisible que la notificación fehaciente sea sustituida por otras formas de notificación

${ }^{11}$ Véase GIL ROBLES Y GIL-DELGADO, José M. ${ }^{a}$, Comentarios prácticos a la Ley de Arrendamientos Rústicos, 2. ${ }^{a}$ ed., Civitas, Madrid, 1982, p. 255; COBACHO GÓMEZ, José Antonio, Estudios sobre la Ley de Arrendamientos Rústicos, Universidad de Murcia, Murcia, 1986, p. 179.

${ }^{12}$ LLOMBART, M. ${ }^{\mathrm{a}}$ de los Desamparados, «Los derechos de adquisición preferente de fincas rústicas a favor de los arrendatarios», $R D P, 1983$, núm. 67, p. 360. La STS de 29 de enero de 1973 (RJA 180) admite expresamente la validez de notificación realizada mediante acto de conciliación. 
siempre que quede probado que ha proporcionado un conocimiento completo de la transmisión. Así fue en el caso contemplado en el que la notificación se llevó a cabo en una reunión celebrada por el comprador con los arrendatarios. No obstante, la falta de validez de la notificación efectuada de esta manera se basa en que en la reunión no se informó cumplidamente a los arrendatarios de cuantas circunstancias eran requeridas en la LAR de 1980. La STS de 13 de diciembre de 2006 (RJA 9734) considera probado el conocimiento de la adjudicación de la finca al rematante, junto con sus condiciones, al estar personado en el juicio ejecutivo. Por su parte las SSTS de 17 y 19 de enero de 2007 (RJA 670 y 1266) declaran probado que el arrendatario tuvo conocimiento suficiente de la transmisión por la aportación del contrato privado de compraventa al interdicto promovido por él frente al comprador.

Ahora bien, en relación con lo dicho por el Tribunal Supremo es menester efectuar una puntualización: la equivalencia declarada debe entenderse circunscrita al ámbito sustantivo al producir igualmente la iniciación del término de caducidad, de modo que le queda vedado al arrendatario el ejercicio del retracto una vez transcurrido el plazo. Cosa distinta es que pueda producir los efectos de la notificación fehaciente por lo que se refiere a la inscripción de la transmisión en el Registro de la Propiedad. Con ello quiero decir que, en ninguno de los supuestos vistos, el comprador debería entenderse liberado de la carga de acreditar al Registrador que ha cumplido con este requisito (argumento ex art. 22.3 y 4 LAR 2003).

\section{EL CONOCIMIENTO DE LA TRANSMISIÓN}

Como ya hemos señalado, el conocimiento de la transmisión funciona como dies a quo del cómputo del plazo para retraer en defecto de notificación. Quiere esto decir que cuando hablamos de conocimiento de la transmisión, la Ley se refiere a todos aquellos supuestos en que el arrendatario consigue la información necesaria para la actuación de su derecho sin que se la hayan proporcionado las partes en la venta causal del retracto. Se trata de un conocimiento exógeno que, como explica el legislador, ha adquirido el arrendatario con derecho de retracto "por cualquier otro medio" que no sea la notificación del propietario o del comprador.

Pero el conocimiento no sólo opera a falta de notificación - aunque este sea con mucho el supuesto más frecuente-, hemos visto que también determina el inicio del plazo de caducidad en aquellas hi- 
pótesis en que resulte acreditado que el conocimiento de transmisión es anterior a la notificación del adquirente.

\section{A) Características del conocimiento exigible}

Una cuestión que ha generado abundante jurisprudencia es la determinación de los caracteres que el conocimiento de transmisión ha de tener para poner en marcha el plazo de ejercicio del retracto. En casi todos los supuestos en los que el Tribunal Supremo se ha pronunciado sobre cuáles han de ser los requisitos del conocimiento como dies a quo del plazo para retraer, el supuesto de hecho en litigio presenta similares características: el arrendatario ejercita su derecho de retracto, sin que el propietario le haya notificado la transmisión, cuyo conocimiento le ha llegado por otros medios, y en el juicio se discute si la acción ha caducado, a consecuencia de la distinta apreciación de los litigantes sobre la fecha en que el arrendatario conoce la transmisión.

Al respecto se defiende la tesis según la cual no basta al retrayente saber que se ha producido la enajenación de la finca arrendada; antes bien, sólo un conocimiento completo y perfecto de las condiciones de la venta tendrá entidad como para iniciar el plazo del retracto, ya se haya obtenido mediante la notificación, ya sea por cualquier otro medio. En justificación de dicha exigencia aduce el Tribunal Supremo que sólo en ese caso el retrayente podrá decidir con fundamento si le interesa o no ejercitar el retracto, es decir, si conviene a sus disponibilidades económicas adquirir la finca en las mismas condiciones que el actual propietario lo hizo del primitivo arrendador.

No obstante, podemos apreciar diferencias de matiz entre lo dicho en las numerosas sentencias que se han dictado sobre esta cuestión. En algunas resoluciones se utilizan adjetivos contundentes dirigidos a poner de manifiesto la necesidad de un conocimiento absoluto y total de la transmisión. Entre otras cabe hacer referencia a las siguientes: la sentencia de 29 de abril de 1943 (RJA 638) se apoya para negar la caducidad de la acción de retracto en que: «no consta que el conocimiento fuera cabal, exacto, en todos los detalles»; en la de 19 de noviembre de 1948 (RJA 1403) se manifiesta que el conocimiento de la transmisión ha de ser "completo, sin deficiencia alguna»; la STS de 1 de diciembre de 1959 (RJA 4606), sin escatimar en adjetivos calificativos, habla de un conocimiento "pleno, cabal, cierto, completo, exacto, perfecto, de las condiciones esenciales y no esenciales». Y por 
ello declara la insuficiencia de la notificación efectuada al arrendatario en la que se omitía toda referencia al pacto por virtud del cual todos los gastos del contrato de compraventa correspondían al comprador. Se afirma, por ende, su inaptitud para iniciar el plazo para retraer; análogas expresiones se utilizan en las SSTS de 21 de marzo de 1969 (RJA 3662), 30 de octubre de 1972 (RJA 4672), 8 de octubre de 1975 (RJA 3483), 6 de febrero de 1979 (RJA 437), 12 de diciembre de 1986 (RJA 7436) 6 de junio de 1988 (RJA 4820), 14 de noviembre de 1991 (RJA 8114), 6 de febrero de 1992 (RJA 834), 14 de noviembre de 1991 (RJA 8114), 2 de diciembre de 1994 (RJA 7850) ${ }^{13}, 25$ mayo 2001 (RJA 3382), 14 de noviembre de 2002 (RJA 9919), 13 de noviembre de 2006 (RJA 9025) y 17 de enero de 2007 (RJA 670).

Hay un grupo minoritario de sentencias, anteriores en el tiempo, que ciñen el saber del retrayente a las condiciones esenciales de la transmisión, entendiendo por tales las que permiten decidir al retrayente, sin más averiguaciones y sin posible error, la conveniencia de adquirir finca arrendada a través del retracto. A modo de ejemplo cabe citar las SSTS de 13 de diciembre de 1940 (RJA 459), 2 de diciembre de 1941 (RJA 1402), 12 de mayo de 1942 (RJA 716), 9 de noviembre de 1945 (RJA 1341) y 29 de enero de 1973 (RJA 180). La última sentencia citada destaca entre estas condiciones esenciales el precio y las modalidades de pago. Estas sentencias merecen ser tenidas en cuenta ya que la doctrina que consagran coincide con el artículo 22.2 LAR 2003 cuando dice que en la notificación para el tanteo deberá hacerse constar el precio y las condiciones esenciales de la transmisión. ¿La cuestión es si nos encontramos ante doctrinas diversas contradictorias entre si?

Prima facie, el primer grupo de sentencias adopta una posición más rigurosa que el segundo en cuanto a los requisitos que debe reunir el conocimiento como inicial del plazo para retraer. Especialmente cuando el Tribunal Supremo insiste que el conocimiento debe extenderse a todas condiciones, las esenciales y las que no lo son, parece que el arrendatario debe conocer todo, lo que le importa, y lo que no le importa. Así entendida la doctrina sobre los requisitos del conocimiento de la transmisión, es absurda por draconiana. Por ello, es menester encontrar una interpretación más lógica. Y esto se consigue atendiendo a la finalidad que cumple la regla de acuerdo con la

13 Véase SÁNCHEZ HERNÁNDEZ, Ángel, «Comentario a la STS de 2 de diciembre de 1994», CCJC, 1995, núm. 39, pp. 593 a 599, donde hace un repaso de la doctrina tradicional del TS sobre las características que ha de reunir el conocimiento de la transmisión para poner en marcha el plazo del retracto. 
cual, en defecto de notificación, el plazo para retraer no se computa hasta el momento en que el arrendatario conozca la transmisión. Esto es, lo que persigue esta regla es que el plazo que hace caducar el retracto no comience hasta que el arrendatario verdaderamente pueda hacer efectivo su derecho — ex artículo 1.969 CC_- porque se trata de que conozca la extensión del derecho que puede adquirir y la contraprestación que ha de realizar por su adquisición, dicho en términos vulgares, el coste económico de su adquisición.

Es obvio que el arrendatario debe conocer el precio de la transmisión, así como los gastos que haya generado, pues de conformidad con el artículo 1.518 del Código civil no podrá hacer efectivo el retracto si no reembolsa al comprador estas cantidades. Es más difícil precisar cuáles son las demás condiciones de la transmisión que debe conocer el arrendatario. Es el contenido del derecho de retracto lo que nos da la medida para desvelar este enigma. De conformidad con el artículo 1.521 del Código civil el retrayente tiene derecho a adquirir la finca subrogándose en las mismas condiciones que el comprador. La cuestión, por tanto, es precisar cuáles son esas condiciones en las que se ha de subrogar el retrayente. Se trata de que el arrendatario sepa qué derecho va adquirir y cuánto le va a costar. Lo que justamente dice el artículo 1.521 del Código civil es que la medida de su adquisición viene dada por la del comprador. Por consiguiente va a adquirir idéntico derecho de propiedad que el comprador y por la misma contraprestación en términos económicos. Esto significa que:

- Por un lado, el arrendatario tiene que conocer todas aquellas condiciones que definan el perfil del derecho de dominio al que accede en virtud del retracto, cuáles son sus cargas y limitaciones, por ejemplo, si la propiedad del bien está gravada con hipoteca u otro derecho real limitado, si la adquisición del dominio se ha sometido a condición suspensiva o resolutoria, o a término final o inicial, o si la cosa se ha vendido con pacto de retro o con pacto de reserva de dominio, o el vendedor se ha reservado el derecho de vuelo, o cualquier otra condición o pacto que module y defina los contornos del derecho real de dominio que va a adquirir el retrayente ${ }^{14}$.

${ }^{14}$ Véase art. 9.2 LH cuando exige que en la inscripción en el Registro de la Propiedad deberá constar «[l]a naturaleza, extensión y condiciones suspensivas o resolutorias, si las hubiere, el derecho que se inscriba, y su valor, cuando constare en el título». 
- Asimismo es preceptivo que conozca el precio que debe pagar por ejercitar su derecho a adquirir la finca, en su caso las modalidades de pago, así como los gastos del contrato: en definitiva, se trata de que el arrendatario conozca todas aquellas cláusulas o circunstancias de contenido económico para decidir cabalmente si el interesa o no ejercitar el derecho ${ }^{15}$.

En suma, parece que, con estas formulaciones aparentemente tan diferentes, en realidad todas las sentencias vienen a decir lo mismo: la necesidad de que el retrayente conozca aquellas circunstancias que puedan influir en su decisión de ejercitar o no el retracto. Esto es, todas y cada una de las condiciones de la venta que deban ser tenidas en cuenta por el arrendatario para tomar una decisión fundamentada, que justamente se corresponden con las que merecen ser consideradas «condiciones esenciales» de la transmisión: el precio pagado por el comprador y las condiciones en que se transmite el derecho de propiedad en que se va a subrogar el retrayente, tal y como dispone el artículo 1.521 del Código civil. Estos son los únicos extremos que le afectan si tenemos en cuenta el arrendatario tiene derecho a adquirir sobre la finca arrendada un derecho de propiedad idéntico al que iba a adquirir o adquirió el comprador y por el mismo precio que había pagado aquel ${ }^{16}$.

En relación con la cuestión que nos ocupa existe una diferencia entre la vigente LAR 2003 y la de 1980: mientras que la anterior LAR se refería al conocimiento de las condiciones de la transmisión, la actual, efectúa un acercamiento a la LAU 1994, en cuanto matiza esta exigencia ciñéndola a «las condiciones esenciales de la transmisión», lo que parece confirmar la idea que estoy defendiendo.

Otra ventaja de esta interpretación es que supone la existencia de una jurisprudencia unánime en cuanto disuelve la contradic-

15 COCA PAYERAS, Miguel/MUNAR BERNAT, Pedro A., "Artículo 25», Comentarios a la Ley de Arrendamientos Urbanos, (coordinados por Carlos Lasarte Álvarez), Tecnos, Madrid, 1996, p. 696 y RODRÍGUEZ MORATA, Federico A., Derecho de tanteo y retracto en la Ley de Arrendamientos Urbanos de 1994, Aranzadi, Pamplona, 1996, p. 155.

16 Se separa de esta lógica la STS de 20 de mayo de 1981 (RJA 2083) que después, de hacer constar la necesidad de un conocimiento: "pleno, cabal, cierto, completo, exacto, perfecto, de todas las condiciones esenciales y no esenciales», sostiene que el conocimiento del pacto según el cual han de ser de cuenta del comprador los gastos de otorgamiento de escritura pública es intrascendente a los efectos del retracto. Para nada se puede tildar de irrelevante este pacto si tenemos en cuenta que a tenor del artículo 1.518 del Código civil el retrayente debe reembolsar al comprador «los gastos del contrato y cualquier otro pago legítimo hecho para la venta». 
ción aparente entre los dos grupos de sentencias que he distinguido. Dicho esto, la cuestión es: ¿Cúal es el motivo de que en determinados supuestos el Tribunal Supremo se haya manifestado en unos términos tan tajantes y exigentes? El origen de esta jurisprudencia que adopta una formulación tan exigente, hay que buscarlo en la solución ideada por el Tribunal Supremo en aplicación de la LAR de 1935 para frenar la tendencia, casi irreprimible, de los compradores a hurtar al arrendatario el conocimiento de la transmisión, que al mismo tiempo, en el colmo de la mala fe, trataban de ampararse en el conocimiento exógeno adquirido por el comprador para alegar que el retracto había sido ejercitado fuera de plazo. Esta conducta desleal era especialmente preocupante con una legislación carente de un mecanismo legal que estimulase a los compradores a notificar la transmisión (bajo la vigencia de la LAR 1935 nada impedía al comprador que no cumplía con el deber o carga de notificar la transmisión al arrendatario, inscribir su adquisición al Registro de la Propiedad). Ante esta situación de lo que se trataba con un requerimiento tan exigente es evitar que, en ausencia de notificación por parte del comprador, el conocimiento de la transmisión por cualquier otro medio, pusiera en marcha el plazo para ejercitar el retracto.

Hoy la situación ha cambiado. El comprador que no notifica su adquisición tiene vedado el acceso al Registro de la Propiedad, con todas las ventajas que esto conlleva (art. 22.4 LAR 2003). Sin embargo, nuestro Tribunal Supremo sigue insistiendo en el requerimiento de un conocimiento exhaustivo, lo que probablemente se debe, en parte, a la inercia jurisprudencial y en parte, por una finalidad preventiva, dado que la inmensa mayoría de los casos de ejercicio de retracto que llegan a los Tribunales el retrayente puede actuar su derecho gracias a un conocimiento exógeno.

\section{B) Prueba del hecho y de la fecha del conocimiento}

Otra cuestión de palmaria importancia es la determinación de la fecha en que el arrendatario conoció la enajenación de la finca a los efectos de determinar si el retracto fue ejercitado dentro de plazo. Por ello es frecuente que en los juicios de retracto el demandado adquirente se esfuerce en demostrar que dicho conocimiento lo obtuvo el retrayente antes de los sesenta días hábiles previos a aquél en que ejercitó la acción de retracto. Ahora bien, tiene declarado la jurisprudencia que corresponde al comprador demandado y no al actor 
retrayente probar que la fecha de conocimiento es anterior a la alegada en la demanda ${ }^{17}$.

Sin embargo, es evidente la dificultad que presenta la prueba del hecho del conocimiento, al tratarse de una situación fáctica, mientras no haya hechos que la exterioricen, frente a la certeza y seguridad que implica la notificación fehaciente de la escritura de enajenación. La Ley no impone una forma determinada de obtención del conocimiento, así el artículo 22.2 LAR de 2003 hace referencia al hecho de éste se haya adquirido "por cualquier medio».

A este respecto cabe citar la Sentencia STS de 12 de febrero de 1991 (RJA 1198) como uno de los supuestos en los que se prueba que el arrendatario conoció la transmisión antes de recibir notificación del nuevo propietario. En la misma se declara que la acción de retracto ejercitada el 31 de enero de 1985 lo fue fuera de plazo. Se desestima la alegación del retrayente que afirma que el plazo no se inició hasta el 4 de junio de 1985, fecha en la que se le efectuó notificación directa y expresa de la transmisión, cuando con el requerimiento para que desalojase la finca se acompañó la escritura pública de venta. Por el contrario, la sentencia estima que el arrendatario adquirió un conocimiento completo de las condiciones de la venta, mucho antes, el 24 de julio de 1978, cuando se otorgó la escritura pública de venta. En efecto, quedó probada la presencia del arrendatario en esa fecha en la notaría, así como que rechazó la oferta de compra del propietario por desacuerdo con las condiciones de la venta de la finca arrendada.

La rigurosa doctrina sobre las cualidades que debe reunir el conocimiento de transmisión, contrasta con la flexibilidad del Tribunal Supremo a la hora de apreciar la concurrencia de un conocimiento suficiente a través de cualquier medio de prueba, incluida la prueba de presunciones (art. 386 LEC de 2000). Véanse a este respecto las SSTS de 30 de junio de 1983 (RJA 3695) ${ }^{18}, 19$ de julio

17 SSTS de 18 de junio de 1949 (RJA 734), 20 de febrero de 1956 (RJA 1503), 9 de octubre de 2007 (RJA 6810), 13 de octubre de 2008 (RJA 5689).

18 En la STS de 30 de junio de 1983 (RJA 3695) el TS da por buena la apreciación efectuada por la sentencia recurrida que en aplicación de la prueba de presunciones llega a la conclusión de que el demandante conoció la transmisión antes de los tres meses previos a la presentación de la demanda, conocimiento que deduce del hecho de que inmediatamente después de la transmisión el comprador inicio importantes obras de mejora en la finca arrendada, sin más reacción por parte del arrendatario que la «muy tardía» de introducir allí a pastar a su ganado y obstaculizar la riega. La Sentencia de 19 de julio de 1988 (RJA 5994) declara admisible que mediante la prueba de presunciones se llegue a la conclusión de que el arrendatario tuvo conoci- 
de 1988 (RJA 5994) y la Sentencia de la AT de Zaragoza de 19 de junio de $1987^{19}$.

\section{C) ¿Es equiparable el conocimiento posible al conocimiento efectivo de la venta?}

Finalmente nos queda tratar una cuestión de cierta importancia: ¿es justo equiparar el conocimiento efectivo de las condiciones de la venta a la posibilidad racional de obtenerlo? La respuesta que a esta cuestión se dé evidentemente influirá en la determinación del momento en que debe comenzar a computarse el plazo para retraer. Este problema ha sido abordado frontalmente en varias sentencias que, empero, no postulan una doctrina uniforme.

En las sentencias de 19 de noviembre de 1955 (RJA 2943), 26 de abril de 1965 (RJA 2028), 15 de febrero 1971 (RJA 1335), 29 de enero de 1973 (RJA 180), 15 de diciembre de 1975 (RJA 5087), 30 de abril de 1990 (RJA 2812), 3 de abril de 2001 (RJA 3992), 21 de octubre de 2009 (id CENDOJ 280791100120091000798) se defiende la equivalencia entre la posibilidad de conocimiento y el conocimiento efectivo para computar el plazo del retracto. Se mantiene la doctrina de que el plazo para retraer debe computarse desde el mismo momento en que se comunica al arrendatario o éste llegue a conocer de cualquier otro modo los datos necesarios para que pueda obtener un conocimiento exacto de las circunstancias de la transmisión utilizando los medios de publicidad que dispone el ordenamiento jurídico (artículos 122 LH y $220 \mathrm{RN}$ ). Estos datos son: por un lado, la fecha de otorgamiento de la escritura pública y el Notario autorizante; y por otro lado, los datos indicadores de la inscripción en el Registro inmobiliario. La base de esta doctrina se encuentra en la protección de la seguridad del tráfico jurídico que, como destaca el Tribunal Supremo constituye, el fundamento del breve plazo de caducidad establecido por la Ley. Puesto que en todos los supuestos el arrendatario tuvo a su alcance la posibilidad real y cierta de conocer las circuns-

\footnotetext{
miento de la transmisión en fecha muy anterior a la de ejercicio del retracto dadas las circunstancias personales y familiares concurrentes. En este caso la propietaria vendedora era la suegra del arrendatario y convivía con él.

19 SAT de Zaragoza de 19 de junio de 1987, RGD, 1987, tomo 44, p. 3089. En esta sentencia se declara probado que el arrendatario conoció la transmisión efectuada en 1976 mucho tiempo antes de la presentación de la demanda, por la confianza existente entre arrendatario y propietario, así como por el hecho de que la transmisión figurase inscrita en el Registro desde enero de 1980.
} 
tancias de la enajenación, no hay nada que autorice a prolongar la situación de inseguridad que la pendencia del retracto conlleva. Interesante es la STS 15 de diciembre de 1975 (RJA 5087) cuando explica que, aunque, desde que en 1949 se reformó el artículo 16.4 de LAR, la inscripción no tiene ya la virtualidad por si misma de abrir el cómputo del plazo del retracto porque «no es suficiente medio para que la transmisión llegue a conocimiento del arrendatario», mas si puede ser un medio de conocimiento de la transmisión, siempre que quede probado que el retrayente tuvo noticia del hecho de la inscripción. Lo que no ocurre en el supuesto de hecho que contempla la sentencia. Visto lo cual se niega su eficacia como momento inicial del plazo para retraer.

Más lejos llega la STS de 15 de febrero de 1971 (RJA 1381). En el supuesto enjuiciado el arrendatario conoció el hecho de la venta en el acto de conciliación, que tuvo lugar en marzo de 1969, promovido por el nuevo propietario para la revisión de la renta. En la sentencia se reprueba la conducta del arrendatario porque en la celebración del acto de conciliación no manifestó interés alguno por conocer los términos de la enajenación y pudo asegurarse de la certeza de la transmisión y de sus condiciones acudiendo al Registro dado que la enajenación figuraba inscrita desde enero de 1969. Así las cosas, el Tribunal Supremo aprecia la caducidad de la acción de retracto: "por la consideración de que la fijación de su plazo, el de tres meses en este caso, para el ejercicio de una acción obedece ciertamente a la necesidad de que la seguridad jurídica no esté pendiente "sine die" de la actividad de cualquier persona una vez que pueda y deba ejercitarla». La singularidad de éste supuesto es que no consta en la sentencia que el arrendatario conociese el hecho de la inscripción. A pesar de ello el Tribunal Supremo considera que debió hacer uso de la publicidad registral para conseguir una noticia exacta de la venta.

La STS de 3 de abril de 2001 (RJA 3992) declara la caducidad de la acción de retracto toda vez que el dies a quo del plazo para retraer tuvo lugar desde la notificación por carta de la compraventa realizada siendo inadmisible su prolongación a la fecha de la retirada de la notaría de una copia de la escritura otorgada.

Por último, en el supuesto de la STS 21 de octubre de 2009 (id. CENDOJ 280791100120091000798) tanto en primera instancia como en apelación el retracto es desestimado al entender que la acción estaba caducada por haberse ejercitado fuera de plazo. A la misma conclusión llega el Tribunal Supremo con fundamento en que el recurrente ha sabido de la existencia de la compraventa de la finca liti- 
giosa el 25 de febrero de 2002, fecha en que recibió por conducto notarial la certificación del Registro de la Propiedad, donde figuraba inscrita la transmisión en el Registro de la Propiedad en el día 16 de febrero del mismo año, no obstante procedió a deducir la demanda de retracto el 11 de julio de 2002, cuando y había transcurrido un plazo muy superior a los sesenta días hábiles desde que tuvo conocimiento de la transmisión. El Tribunal Supremo se expresa con toda claridad a la hora de calificar la conducta del arrendatario retrayente: «[1]a demora recién expresada significa que el recurrente ha actuado con negligencia para conseguir los datos concernientes a las condiciones de la enajenación, su precio, el nombre y circunstancias del adquirente y cualesquiera otras que considerara oportunas, para cuyo conocimiento sólo era necesario acudir al Registro de la Propiedad en tiempo correcto y el mismo indicó que ha sabido los términos exactos de la compraventa el 8 de mayo de 2002, al solicitar la correspondiente certificación registral» $\left(\mathrm{F} . \mathrm{D}^{\circ} .1^{\circ}\right)$.

La doctrina expuesta supone que:

- El interés protegido por estas sentencias es el de la seguridad del tráfico: no tiene sentido alargar la amenaza que implica el retracto, si el arrendatario está en condiciones de ejercitarlo.

- En estos supuestos el plazo para retraer no comienza cuando el arrendatario obtenga un conocimiento pleno, exacto, perfecto, etc., de la transmisión merced a la utilización de los medios de publicidad antes indicados. Por el contrario, el cómputo se anticipa a la fecha en la que surja la posibilidad real de conseguir un conocimiento idóneo para ejercitar el retracto. Ello parece lógico, pues de otro modo sería tanto como otorgar al arrendatario la facultad de elección del momento inicial del plazo, pudiendo demorar a su gusto el momento de obtención de dicho conocimiento.

- El Tribunal Supremo califica de negligente la conducta del arrendatario retrayente que tuvo al alcance de su mano obtener un conocimiento de la transmisión revestido de las cualidades necesarias para ejercitar el retracto.

No obstante, existen sentencias que parecen seguir la tesis contraria. Así la sentencia de 21 de marzo de 1969 (RJA 3622) declara expresamente que el plazo: «no se comienza a contar a partir de la fecha del posible conocimiento de la transmisión, sino a partir de aquella en que se tenga tal conocimiento que ha de ser cabal y perfecto». Similares afirmaciones se contiene en la sentencia de 18 de oc- 
tubre de 1980 (RJA 3269), si bien se efectúan al objeto de precisar que la inscripción en el Registro de la Propiedad ya no funciona como raíz para el cómputo del plazo de caducidad del retracto. En aplicación de la LAR de 1980 sigue esta tendencia la sentencia de 6 de febrero de 1992 (RJA 834). Precisamente esta resolución desestima la invocación del recurrente de aplicar al supuesto de hecho litigioso la doctrina contenida en la sentencia de 19 de noviembre de 1955 (RJA 2943). El Tribunal Supremo dice que la doctrina contenida en aquella sentencia ha sido superada por otras más recientes, que parten de la base de que: "no sólo basta que el retrayente tenga conocimiento de la venta que se ha efectuado e incluso de la identificación de las adquirentes, sino que su saber ha de abarcar los detalles completos precisos y exactos de la transmisión, tanto esenciales como no esenciales». En apoyo de esta tesis cita la Sentencia de 20 de mayo de 1981 (RJA 2083).

En el caso de la STS de 14 de diciembre de 2009 (id. CENDOJ 2879110120091000798) confirma la sentencia de segunda instancia estimatoria del retracto. El motivo de discusión se ciñe a si el retracto fue ejercitado en plazo. El juzgado de primera instancia apreció la caducidad aunque el vendedor no hizo la notificación y el conocimiento de la transmisión lo entendió cumplimentado por el inscripción en el Registro de la Propiedad por cuanto la misma supone una presunción iuris et de iure de la posibilidad de conocimiento de la transmisión por el retrayente. El Tribunal Supremo niega que la inscripción en el Registro de la Propiedad por si sola implique la posibilidad de conocimiento de la transmisión por el retrayente con fundamento en la siguiente argumentación (F. D. ${ }^{\circ} 2^{\circ}$ ):

«(...) [N]o pueden las partes que realizaron la transmisión de la finca y que no cumplieron el deber que impone el artículo 87 de la Ley de Arrendamientos Rústicos de 1980, faltando así a la buena fe precontractual, pretende aprovecharse y beneficiarse de ello y buscando una interpretación que le es favorable a la norma, burlar el derecho de retracto que la Ley reconoce al arrendatario, como expresión de la función social del derecho de propiedad. Así esta Sala se pronuncia claramente en el sentido de que en el retracto, la inscripción en el Registro de la Propiedad no supone el conocimiento cabal, preciso y exacto, ni es presunción iuris et de iure del mismo, que constituya dies a quo del plazo de caducidad que impone la Ley».

Si profundizamos en el sentido de las sentencias citadas, una vez más podremos comprobar que verdaderamente no existe contradicción con la doctrina legal de las resoluciones anteriores: una vez más la clave está en las características de los supuestos que contem- 
plan las resoluciones citadas, ya que la conducta de las partes en conflicto presenta características diversas. Mientras que en el primer grupo de sentencias, o bien es el propio adquirente quien notifica al arrendatario el hecho de la transmisión, haciéndole saber además los datos necesarios para que pueda ejercitar con conocimiento de causa su derecho acudiendo al Registro o a la Notaria donde se otorgo la escritura pública; o bien aunque el comprador no cumple con su obligación de notificar, tampoco trata de ocultar su adquisición al arrendatario, que por cualquier otro medio conoce los datos antes enunciados: en el caso de la STS de 1 de noviembre de 1955 (RJA 2943) el adquirente inmediatamente después de consumar su adquisición realiza importantes obras de mejora en la finca arrendada. Ello pone de manifiesto que el arrendatario no pudo ignorar que la enajenación se había efectuado, pese a lo cual el arrendatario deja transcurrir un lapso de tiempo considerable - algo más de año y medio - sin desarrollar una actividad que estaba al alcance de su mano para obtener un conocimiento suficiente de la transmisión. Por ello declara el Tribunal Supremo que cuando se presentó la demanda, la acción de retracto ya había caducado.

Nada que ver con las respectivas conductas de los sujetos implicados en el segundo grupo de sentencias. En la sentencia de 21 de marzo de 1969 (RJA 3622) el Tribunal Supremo confirma la narración de los hechos en la segunda instancia que declara que los arrendatarios ejercitaron la acción de retracto dentro de los tres meses siguientes a aquel en que tuvieron noticia de la venta. Además se afirma que la demora en el ejercicio del derecho, que tuvo lugar diez años después de la venta de la finca arrendada, es imputable a los demandados, pues no sólo incumplieron su obligación de notificar, sino que trataron por todos los medios de evitar que los retrayentes tomasen conocimiento de la transmisión.

En el caso de la STS de 6 de febrero de 1992 (RJA 834) se transmite la nuda propiedad de seis fincas rústicas arrendadas, reservándose la vendedora el usufructo vitalicio de las mismas. Ni el vendedor ni el comprador comunican la venta al arrendatario. Han de transcurrir siete años para que el arrendatario tenga noticia por primera vez del hecho de la transmisión. Una vez fallecida la usufructuaria el adquirente consolida el pleno dominio de la finca, por lo cual decide comunicar notarialmente al arrendatario el hecho de la transmisión con el único fin de requerirle para que desde entonces le abone la renta pactada. Esta conducta contrasta con la del arrendatario: tan pronto como conoce el hecho de la venta despliega toda la actividad necesaria para enterarse de sus condiciones. Dos meses después de 
haber tenido noticia de la venta promueve acto de conciliación solicitando al nuevo propietario la exhibición de las escrituras públicas de enajenación. El demandado no comparece a dicho acto, ante lo cual la actora acude al Registro de la Propiedad. Pero en la certificación registral no hay constancia tabular de una de las fincas vendidas y arrendadas, con lo que, a pesar de las pesquisas efectuadas, el arrendatario se ve constreñido a ejercitar el retracto con un conocimiento insuficiente de la transmisión. Como destaca esta sentencia, mientras que el arrendatario ejercita diligentemente su derecho de retracto, el nuevo propietario adopta una conducta claramente contraria a las exigencias de la buena fe.

\section{CONCLUSIONES}

Uno de los supuestos problemáticos que se plantean en el ejercicio del retracto y que destacan por su reiteración en la jurisprudencia es la determinación del momento en que el arrendatario adquiere conocimiento de la transmisión como dies a quo del plazo para retraer. La jurisprudencia tiene declarado que dicho conocimiento debe ser completo, cumplido y cabal, abarcando una noticia exacta de todos los extremos de la transmisión, esenciales y no esenciales. Por tanto, parece que el Tribunal Supremo exige que el retrayente adquiera un conocimiento total y absoluto de la transmisión, aplicando un rigor extremo para que el conocimiento tenga virtualidad. La causa de una jurisprudencia tan exigente descansa una vez más en la necesidad de hacer frente a los compradores que no notifican su adquisición al arrendatario y después sostienen que el retracto fue ejercitado fuera de plazo apoyándose en la fecha en que el arrendatario tuvo conocimiento de la venta.

No obstante, tras un análisis pormenorizado de la jurisprudencia, este alto nivel de exigencia resulta matizado y suavizado:

(A) Esta exigencia debe ser interpretada de acuerdo con la finalidad que persigue. Se trata de que el plazo de caducidad no comience en tanto el arrendatario no esté en condiciones de ejercitar el retracto. Así resulta de un grupo minoritario de sentencias que ciñen el saber del retrayente a las condiciones esenciales de la transmisión [SSTS de 13 de diciembre de 1940 (RJA 459), 2 de diciembre de 1941 (RJA 1402), 12 de mayo de 1942 (RJA 716), 9 de noviembre de 1945 (RJA 1341) y 29 de enero de 1973 (RJA 180)]. Por tanto, se trata de que el arrendatario sepa la extensión del derecho que va a adquirir y 
cuanto le va a costar. Esto es, aquellas condiciones de la venta que le permiten decidir fundamente si le interesa o no el retracto, que coinciden con las condiciones esenciales de la transmisión: 1) las condiciones relativas a la extensión del derecho que va adquirir, como sus cargas y limitaciones, o si la adquisición está sometida a término o condición y cualquier otra condición que perfile los contornos del derecho de dominio que va a adquirir el retrayente; 2) el precio y en su caso las modalidades de pago establecidas, así como los gastos del contrato.

(B) Hay un buen número de sentencias que equiparan el conocimiento posible al conocimiento efectivo de la venta [SSTS de 19 de noviembre de 1955 (RJA 2943), 26 de abril de 1965 (2028), 15 de febrero 1971 (1335), 29 de enero de 1973 (RJA 180), 15 de diciembre de 1975 (RJA 5087), 30 de abril de 1990 (RJA 2812), 3 de abril de 2001 (RJA 3992)] y 14 de diciembre de 2009 (id. CENDOJ 28079110012009100798). Esto significa que el plazo para retraer debe computarse desde el instante en que el arrendatario tenga a su disposición los datos necesarios para conseguir un conocimiento exacto de las circunstancias de la transmisión utilizando los medios de publicidad que dispone el ordenamiento jurídico (artículos $122 \mathrm{LH}$ y $220 \mathrm{RN}$ ). Estos datos son, por un lado, la fecha de otorgamiento de la escritura pública y el Notario autorizante, y por otro lado, los datos indicadores de la inscripción en el Registro inmobiliario. En ese caso el cómputo del plazo de caducidad del retracto se adelanta a la fecha en que surgió la posibilidad real de conseguir el conocimiento idóneo para ejercitar el retracto. El interés protegido por estas sentencias es el de la seguridad del tráfico: no tiene sentido alargar la amenaza que implica el retracto, si el arrendatario está en condiciones de ejercitarlo. 
